\title{
Growth, Duplication and Lateral Mutual Compressive Deformation of Akouemma hemisphaeria on the Seafloor of Okondja Basin at 2.2 Ga (Gabon)
}

\author{
Ambroise Edou-Minko1 ${ }^{*}$, Mathieu Moussavou', Tomohiko Sato², Yusuke Sawaki ${ }^{3}$, \\ Simplice Ndong Ondoㄹ, Richard Maire ${ }^{4}$, Guillaume Fleury ${ }^{5}$, Michel Mbina Mounguengui ${ }^{1}$, \\ Anders Kaestner6, Richard Ortega7, Stéphane Roudeau7, Asuncion Carmona7, \\ Makaya Mvoubou', Benjamin Musavu Moussavou', Osamu Sasaki ${ }^{8}$, Shigenori Maruyama ${ }^{2}$ \\ ${ }^{1}$ Université des Sciences et Techniques de Masuku, Franceville, Gabon \\ ${ }^{2}$ Earth-Life Science Institute (ELSI), Tokyo Institute of Technology, Tokyo, Japan \\ ${ }^{3}$ Department of Earth Science and Astronomy, Graduate School of Arts and Sciences, The University of Tokyo, Tokyo, Japan \\ ${ }^{4}$ UMR 5319 Passages, Maison des Suds, CNRS-Université Bordeaux-Montaigne, Pessac, France \\ ${ }^{5}$ Muséum d'Histoire Naturelle de Toulouse, Toulouse, France \\ ${ }^{6}$ Laboratory for Neutron Scattering and Imaging, Paul Scherrer Institut, Villigen, Switzerland \\ ${ }^{7}$ CENBG, Univ. Bordeaux, CNRS, IN2P3, UMR 5797, Gradignan, France \\ ${ }^{8}$ Tohoku University Museum, Université de Tohoku, Sendai, Japan \\ Email: *edouminko@gmail.com
}

How to cite this paper: Edou-Minko, A., Moussavou, M., Sato, T., Sawaki, Y., Ndong Ondo, S., Maire, R., Fleury, G., Mbina Mounguengui, M., Kaestner, A., Ortega, R., Roudeau, S., Carmona, A., Makaya Mvoubou., Musavu Moussavou, B., Sasaki, O. and Maruyama, S. (2017) Growth, Duplication and Lateral Mutual Compressive Deformation of Akouemma hemisphaeria on the Seafloor of Okondja Basin at $2.2 \mathrm{Ga}(\mathrm{Ga}-$ bon). International Journal of Geosciences, 8, 1172-1191.

https://doi.org/10.4236/ijg.2017.89067

Received: August 4, 2017

Accepted: September 25, 2017

Published: September 28, 2017

\begin{abstract}
A colony of macro-fossils Akouemma hemisphaeria has been described in the Paleoproterozoic sedimentary basin of Okondja, Gabon. These fossils are classified into two groups according to their spheroidal or elongated forms. The spheroidal shapes are similar, have a tripartite structure with two hemispheres and a median disc and gradually pass to the elongated forms. These elongated forms have a pronounced bipartite tendency to two "hemispheres" separated by a median surface, and often have several ovoid "pieces" attached. The elongated specimens show both lateral growth marks and signs of fission. Growth marks are characterized by unidirectional homogeneous side elongations and lateral bud-like protuberances. The signs of fission are marked by circular furrows perpendicular to the direction of elongation, called "constriction furrows" with varying depths depending on the degree of fission of the specimen and internal vertical "division planes". All of these ovoid and elongated specimens have undergone significant initial deformations due mainly to mutual lateral compressions in tabular beds. The Akouemma hemisphaeria macro-organisms, which were primitive probably sessile organisms, lived on
\end{abstract}


Copyright $\odot 2017$ by authors and Scientific Research Publishing Inc. This work is licensed under the Creative Commons Attribution International License (CC BY 4.0).

http://creativecommons.org/licenses/by/4.0/ the seafloor. They provide the oldest known record of macro-organisms on Earth having vegetative growth and asexual reproduction by budding, lateral elongation and fission. Their mutual lateral deformations would result from their growth.

\section{Keywords}

Paleoproterozoic, Francevillian Group, Okondja Basin, Akouemma hemisphaeria, Growth, Duplication

\section{Introduction}

The Paleoproterozoic is one of the most significant periods in the Earth's history, not only for the environmental changes represented by Snowball Earth [1] and Great Oxidation Event [2], but also for the appearance of the eukaryotic fossils [3]. For example, Grypania is a well-known eukaryotic macroscopic compression fossil from 1.9 Ga in Michigan, USA [4]; a colony of Discagma buttonii are macro-fossils discovered in the palaeosols of South African and dated to 2.2 $\mathrm{Ga}$ [5]; however, the biological classifications of these fossils are still under debate. Recently, Gabon came into the spotlight by the discovery of colonial organisms [6] and Akouemma hemisphaeria macrofossils colony [7] [8]. The Elucidation of their life cycles enables us to make a breakthrough to the controversial Paleoproterozoic paleontology.

The macrofossils Akouemma hemisphaeria described in the Paleoproterozoic basin of Okondja are located in the $\mathrm{FB}_{2} \mathrm{~b}$ formations [7] [8] dated at $2191 \pm 13$ Ma [9] (Figures 1(A)-(C)). They are organic macrofossils of ovoid (spheroidal) shape, with $2 \mathrm{~cm}$ of average diameter, consisting of two hemispheres separated by a median disc (Figure 1 (D0), 3); and elongated shapes whose polar diameter is substantially similar to that of the ovoid shapes. These elongated forms rarely exceed $6 \mathrm{~cm}$ in length (Figure 1 (D6, D7), 4-7). A statistical study shows that the transition from spheroidal to elongated forms seems to be gradually (Table 1 , Figure 2). The internal structure is fibro-radial, centrifugal upward in the upper hemisphere and centrifugal downward in the lower hemisphere, initially consisting of fibers and carbon particles [7] [8]. These organisms have undergone significant deformations in tabular beds and hosted a large number of cyanobacteria, filamentous microorganisms, green alga fragments, small unicellular and multicellular organisms and other lenticular and oblong shape bodies; they are, in the history of Earth Sciences, the first Paleoproterozoic organisms described, living in association with a biodiversity of microorganisms [8]. Their fossilization is essentially siliceous to more than $80 \%$, composed of micro-quartz, associated with EPS type calcite, oxides and iron sulphides and secondary-formed clay minerals which perfectly highlight the internal structure of these specimens [7] [8]. 
A

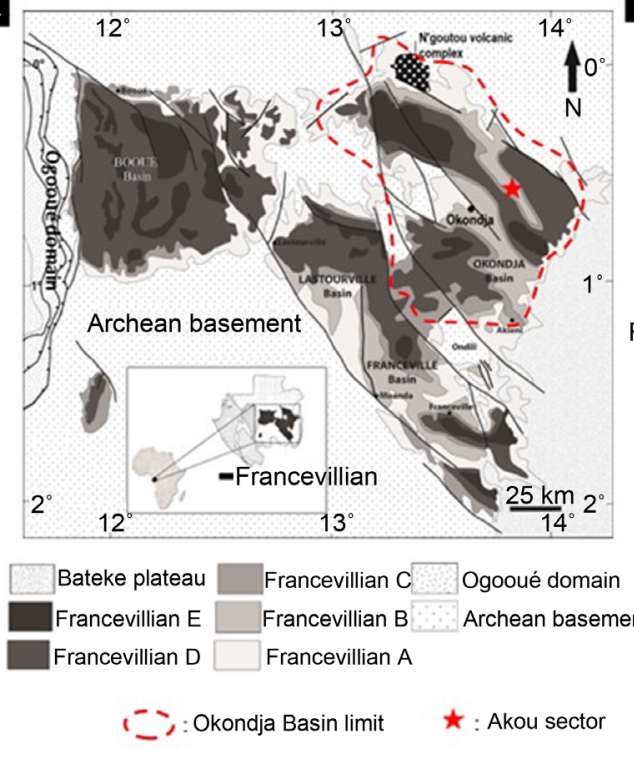

B Okondja Basin C Akou River D
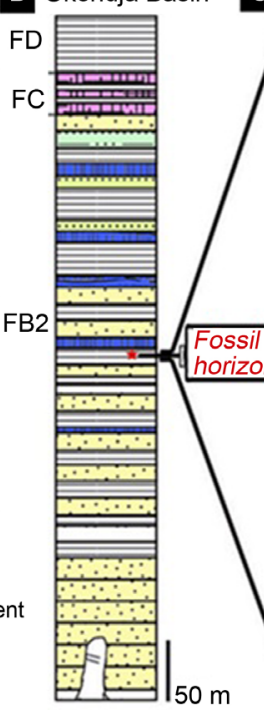

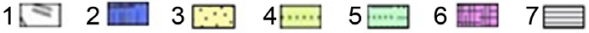

1: Mafic intrusion; 2: Basaltic lava; 3: Sandstone; 4: Siltstone; 5: Pyroclastic sandstone; 6: Chert; 7: Black shale.

Figure 1. (A) Geological map showing the context of fossiliferous Palaeoproterozoic rocks in Gabon. (B) Lithostratigraphy of units FB2, FC and FD in the Okondja Basin. (C) Lithostratigraphy of fossiliferous Akou River. (D) Different forms of Akouemma hemisphaeria (D0-D8). Scale bars: $1 \mathrm{~cm}$. ([7], modified).

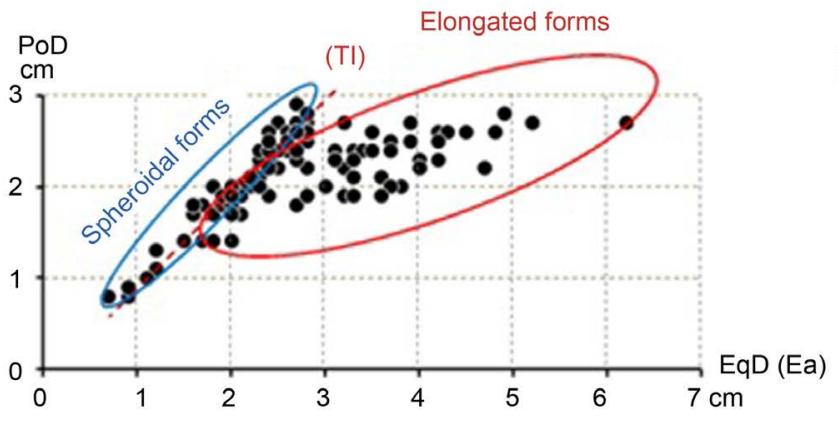

(A)
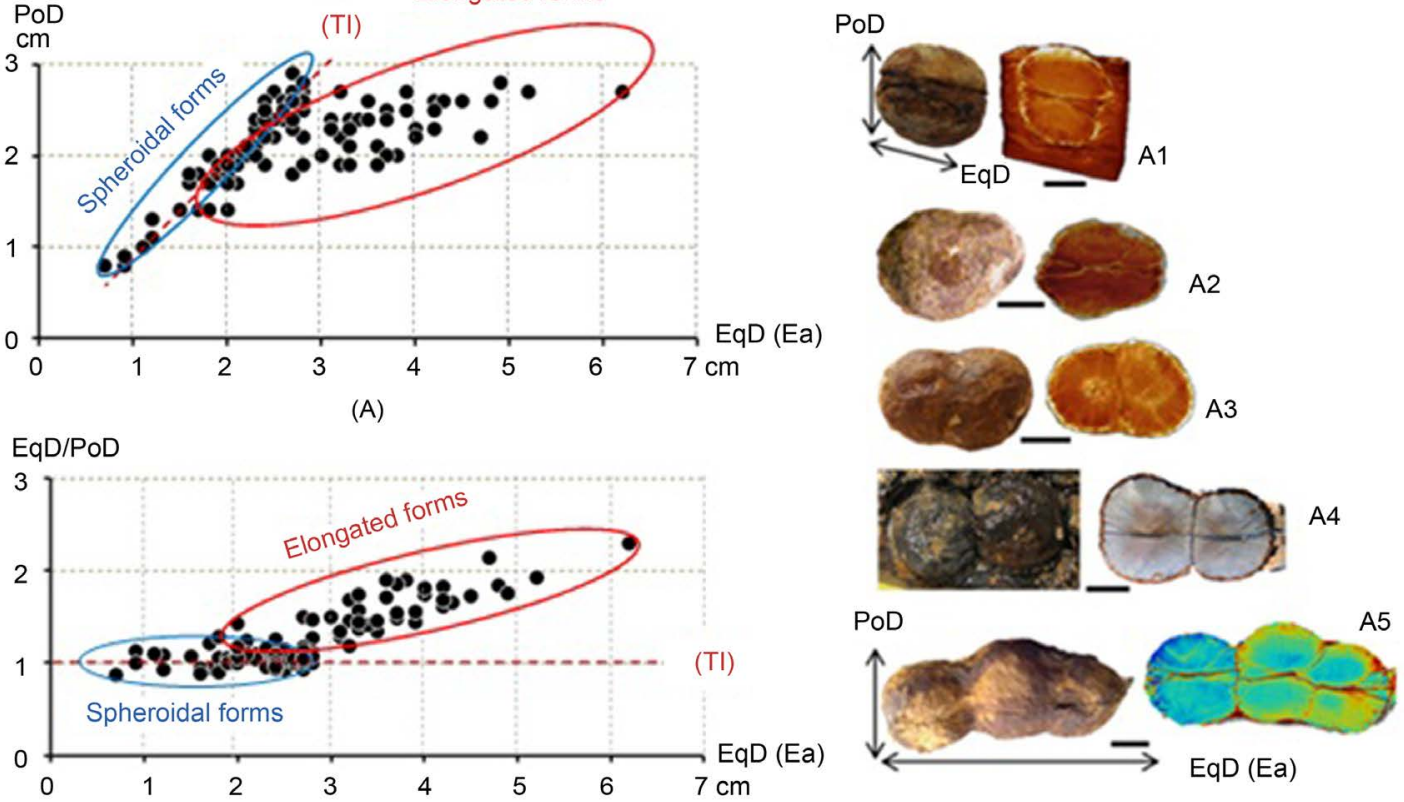

(B)

Figure 2. Graph showing the range of polar diameter (PoD) and equatorial diameter (EqD) in the Akouemma specimens in (A); and the range of report $\mathrm{EqD} / \mathrm{PoD}$ and equatorial diameter in (B). These show a tendency for typical specimens to be ovoid (A1) and the elongated shapes showing a tendency towards lateral growth (A2-A5), "constriction zone" (external furrow) and division (internal division plane) (A3-A5). In the spheroidal forms the polar $(\mathrm{PoD})$ and equatorial $(\mathrm{EqD})$ diameters grow proportionally, and less than $3 \mathrm{~cm}$; in the elongated forms only the equatorial diameter continues to grow, exceeding barely $6 \mathrm{~cm}$. (Ea): Elongation axis, (Tl): Theoretical limit between spheroidal forms and elongated forms. Scale bars: $1 \mathrm{~cm}$. ([8] modified). 
A. Edou-Minko et al.

Table 1. Measurements of polar (PoD) and equatorial (EqD) diameters of specimens Akouemma hemisphaeria.

\begin{tabular}{|c|c|c|c|c|c|c|c|}
\hline $\mathrm{N}^{\bullet}$ & $\begin{array}{l}\mathrm{EqD}, \\
(\mathrm{cm})\end{array}$ & $\begin{array}{l}\text { PoD, } \\
(\mathrm{cm})\end{array}$ & $\mathrm{EqD} / \mathrm{PoD}$ & $\mathbf{N}^{\bullet}$ & $\begin{array}{l}\text { EqD, } \\
(\mathrm{cm})\end{array}$ & $\begin{array}{l}\text { PoD, } \\
(\mathrm{cm})\end{array}$ & $\mathrm{EqD} / \mathrm{PoD}$ \\
\hline 1 & 2.8 & 2.7 & 1.04 & 56 & 1.7 & 1.4 & 1.21 \\
\hline 2 & 2.3 & 2.2 & 1.05 & 57 & 3.2 & 2.7 & 1.19 \\
\hline 3 & 3.5 & 2.6 & 1.35 & 58 & 2.7 & 2.7 & 1 \\
\hline 4 & 2.3 & 2.2 & 1.05 & 59 & 2.4 & 2.4 & 1 \\
\hline 5 & 2.2 & 2 & 1.1 & 60 & 2.8 & 2.6 & 1.08 \\
\hline 6 & 3.1 & 2.4 & 1.29 & 61 & 3.1 & 2.4 & 1.29 \\
\hline 7 & 4.2 & 2.3 & 1.83 & 62 & 4.2 & 2.3 & 1.83 \\
\hline 8 & 3.6 & 2.1 & 1.71 & 63 & 2.1 & 2 & 1.05 \\
\hline 9 & 6.2 & 2.7 & 2.3 & 64 & 2.7 & 1.8 & 1.5 \\
\hline 10 & 1.8 & 2 & 0.9 & 65 & 2.7 & 2.3 & 1.17 \\
\hline 11 & 1.9 & 1.9 & 1 & 66 & 2 & 1.8 & 1.11 \\
\hline 12 & 2.2 & 2.1 & 1.05 & 67 & 2.5 & 2.2 & 1.14 \\
\hline 13 & 2.1 & 2 & 1.05 & 68 & 2.2 & 2.1 & 1.05 \\
\hline 14 & 2.2 & 2 & 1.1 & 69 & 2.6 & 2.4 & 1.08 \\
\hline 15 & 3.1 & 2.3 & 1.35 & 70 & 2.3 & 2.4 & 0.96 \\
\hline 16 & 2.4 & 2.3 & 1.04 & 71 & 2.1 & 1.9 & 1.11 \\
\hline 17 & 3.2 & 1.9 & 1.68 & 72 & 2.5 & 2.4 & 1.04 \\
\hline 18 & 2.4 & 1.9 & 1.26 & 73 & 2.6 & 2.5 & 1.04 \\
\hline 19 & 1.9 & 1.8 & 1.06 & 74 & 2 & 1.4 & 1.43 \\
\hline 20 & 3.9 & 2.6 & 1.5 & 75 & 1.8 & 1.4 & 1.29 \\
\hline 21 & 0.7 & 0.8 & 88 & 76 & 1.9 & 1.9 & 1 \\
\hline 22 & 1.7 & 1.8 & 0.94 & 77 & 2 & 2 & 1 \\
\hline 23 & 0.9 & 0.8 & 1.13 & 78 & 2 & 1.9 & 1.05 \\
\hline 24 & 2.2 & 2.1 & 1.05 & 79 & 2.8 & 2.5 & 1.12 \\
\hline 25 & 0.9 & 0.9 & 1 & 80 & 2 & 1.7 & 1.18 \\
\hline 26 & 1.6 & 1.7 & 0.94 & 81 & 2.8 & 2.6 & 1.08 \\
\hline 27 & 3.2 & 2.2 & 1.45 & 82 & 2.4 & 2.2 & 1.09 \\
\hline 28 & 2.1 & 2 & 1.05 & 83 & 2.8 & 2.8 & 1 \\
\hline 29 & 1.2 & 1.1 & 1.09 & 84 & 2.8 & 2.6 & 1.08 \\
\hline 30 & 3 & 2 & 1.5 & 85 & 2.7 & 2.4 & 1.13 \\
\hline 31 & 2.5 & 2.7 & 0.93 & 86 & 2.4 & 2.4 & 1 \\
\hline 32 & 1.6 & 1.7 & 0.94 & 87 & 2.4 & 2.5 & 0.96 \\
\hline 33 & 3.1 & 2.3 & 1.35 & 88 & 2.7 & 2.6 & 1.04 \\
\hline 34 & 0.7 & 0.8 & 0.88 & 89 & 2.7 & 2.6 & 1.04 \\
\hline 35 & 1.8 & 1.7 & 1.06 & 90 & 3.7 & 2.5 & 1.48 \\
\hline 36 & 2.3 & 2.1 & 1.1 & 91 & 5.2 & 2.7 & 1.93 \\
\hline 37 & 2.7 & 2.9 & 0.93 & 92 & 2.8 & 1.9 & 1.47 \\
\hline 38 & 1.2 & 1.3 & 0.92 & 93 & 3.3 & 2.1 & 1.57 \\
\hline
\end{tabular}




\begin{tabular}{cccccccc}
\multicolumn{2}{l}{ Continued } \\
\hline 39 & 2.3 & 2 & 1.15 & $\mathbf{9 4}$ & 4.9 & 2.8 & 1.75 \\
$\mathbf{4 0}$ & 2.4 & 2.6 & 0.92 & $\mathbf{9 5}$ & 4.5 & 2.6 & 1.73 \\
$\mathbf{4 1}$ & 1.5 & 1.4 & 1.07 & $\mathbf{9 6}$ & 4 & 2.3 & 1.74 \\
$\mathbf{4 2}$ & 3.8 & 2 & 1.9 & $\mathbf{9 7}$ & 3.9 & 2.7 & 1.44 \\
$\mathbf{4 3}$ & 2.2 & 2.1 & 1.05 & $\mathbf{9 8}$ & 3.9 & 2.5 & 1.56 \\
$\mathbf{4 4}$ & 3.3 & 1.9 & 1.74 & $\mathbf{9 9}$ & 4.7 & 2.2 & 2.14 \\
$\mathbf{4 5}$ & 1.9 & 1.8 & 1.06 & $\mathbf{1 0 0}$ & 3.7 & 2.4 & 1.54 \\
$\mathbf{4 6}$ & 2.8 & 2.2 & 1.27 & $\mathbf{1 0 1}$ & 3.6 & 1.9 & 1.89 \\
$\mathbf{4 7}$ & 2.1 & 1.9 & 1.11 & $\mathbf{1 0 2}$ & 4.2 & 2.6 & 1.62 \\
$\mathbf{4 8}$ & 2.3 & 2.3 & 1 & $\mathbf{1 0 3}$ & 4.8 & 2.6 & 1.85 \\
$\mathbf{4 9}$ & 1.1 & 1 & 1.1 & $\mathbf{1 0 4}$ & 4.3 & 2.6 & 1.65 \\
$\mathbf{5 0}$ & 3.3 & 2.4 & 1.38 & $\mathbf{1 0 5}$ & 4.2 & 2.5 & 1.68 \\
$\mathbf{5 1}$ & 3.7 & 2 & 1.85 & $\mathbf{1 0 6}$ & 3.4 & 2.4 & 1.42 \\
$\mathbf{5 2}$ & 2.6 & 2.6 & 1 & $\mathbf{1 0 7}$ & 4 & 2.2 & 1.82 \\
$\mathbf{5 3}$ & 2.5 & 2.4 & 1.04 & $\mathbf{1 0 8}$ & 4.9 & 2.8 & 1.75 \\
$\mathbf{5 4}$ & 2.1 & 1.7 & 1.24 & $\mathbf{1 0 9}$ & 3.3 & 2.3 & 1.43 \\
$\mathbf{5 5}$ & 2 & 2 & 1 & $\mathbf{1 1 0}$ & 3.5 & 2.4 & 1.46 \\
\hline & & & & & & &
\end{tabular}

\section{Material and Methods}

The studied macrofossils are Akouemma hemispheria from Akou River in Okondja basin (Figure 1). The fossils are found from more than 7 layers in the FB2 unit, alternating layers of quartz sandstone and black shale. The main analyses of these specimens are CT analysis, neutron tomography, SEM-EDS, PIXE analysis and a statistical study on the shape and size of specimens. These methods presented herein again, we have already described them [7] [8].

\subsection{Laboratory-Based CT Analysis}

Carl Zeiss Nanotom scanner was used to obtain data on specimens contained in sediments with slices $0.5 \mathrm{~mm}$ thick. On simple samples and specific areas, slices of $17 \mu \mathrm{m}$ and $70 \mu \mathrm{m}$ were analyzed with a Carl Zeiss Metrotom and a Carl Zeiss Metrotom. The best image quality and inter-operability were ensured by exporting all CT and micro-CT data using the DICOM export file format. Processing of 2D and 3D images from the CT and Micro-CT DICOM stacks was performed on a Dell Precision T7400 Dual Quad Core Intel Xeon 3.2 GHz workstation, using $32 \mathrm{~GB}$ of DDR RAM and a Quadro FX 4600 graphics board running VG Studio Max 2.0 and $2.2 \times 64$ from Volume Graphics GmbH. The Micro-XCT-400 system at Tohoku University was used to perform completementary micro-CT analyzes for X-strata; and the photographs of all strata were made using a 3D MOLCER image viewer.

\subsection{Neutron Tomography}

Neutron imaging is an alternative method to X-ray imaging that provides new 
insights in the sample composition. The techniques are similar but the radiation type is changed to neutrons. Neutrons are sensitive to different elements than $\mathrm{X}$-rays and in particular light elements deliver higher contrast in the recorded images to reconstruct a three-dimensional image of a sample [10]. Examples of high contrast elements are hydrogen and lithium, while many metals exhibit low attenuation. This is in particular interesting for the investigation of fossils that often contain iron while the parts of organic origin contains lighter elements [11] [12] [13]. Neutron imaging requires high neutron flux to obtain a good image quality. This can only be obtained at large scale facilities like research reactors or spallation neutron sources. In this investigation computed tomography with neutron radiographs provided $3 \mathrm{D}$ information about the sample composition. The experiments were performed at Paul Scherrer Institut using the cold neutron imaging beam line ICON [14]. The data was acquired using the micro-tomography setup. It provides a $13.5 \mu \mathrm{m}$ pixel size and a field of view of $27 \times$ $27 \mathrm{~mm}^{2}$. A Gadox scintillator with $20 \mu \mathrm{m}$ thickness was used to convert the neutrons to visible light, the light image was captured using a cooled CCD camera (Andor DW436). The CT scan was made over 360 degrees with 625 projections that were reconstructed using the Octopus CT reconstruction software. The reconstruction was made using parallel beam geometry which is a valid approximation due to the high collimation of the neutron beam at ICON. This resulted in a volume data set with a $13.5 \mu \mathrm{m}$ voxel size. The signal to noise ratio of the data was relatively low. Therefore, a denoising filter based on the ROC model in inverse scale space setting [15] was applied using KipTool [refQuoVadis] to improve the image quality without destroying relevant features. Finally, the volume data was visualized and animated using the Drishti 2.5.1 volume rendering software.

\subsection{SEM-EDS}

SEM-EDS (electron microscopy-energy dispersion X-ray spectrometry) analyses were performed on Os-coated samples to investigate the distribution of elements such as potassium, calcium and iron using a Hitachi S-3400N SEM with a Bruker Xflash 5010 at the Tokyo Institute of Technology. Measurements were carried out at an acceleration voltage of $15 \mathrm{kV}$.

\subsection{PIXE Analysis}

PIXE (particle-induced X-ray emission) by nuclear microprode allowed quantitative imaging of the distribution of chemical elements in various types of materials, including fossil samples. In addition, the both PIXE and RBS (Rutherford backscattering spectrometry) combination allowed complete quantification of the concentrations of these chemical elements [16]. A polished section of Akouemma hemisphaeria sample (AKOU16) was analyzed using a PIXE microprobe at CENBG (Bordeaux Gradignan). The $1.775-\mathrm{MeV}$ proton beam used provided information on the distribution of the chemical elements with the 
atomic number $>11$ and with an improvement of the carbon signal RBS by carbon resonance at $1.75 \mathrm{MeV}$. The proton beam concentrated to 2 micrometers at the surface of the sample provided an intensity of $500 \mathrm{pA}$. The raster scanner was used to allow chemical imaging of $1.2 \times 1.2 \mathrm{~mm}^{2}$ of the sample. The chemical maps recorded in a matrix of $256 \times 256$ pixels have a spatial resolution of 4.6 $\mu \mathrm{m} /$ pixel. In the Akouemma hemisphere (AKOU 16), 393 square areas of $1.2 \times$ $1.2 \mathrm{~mm}^{2}$ were each analyzed to cover the entire section of the sample (approximately $576 \mathrm{~mm}^{2}$ ). For specific areas such as carbonate rich regions, higher spatial resolution maps have been generated with a smaller beam $(0.8 \mu \mathrm{m})$ and a lower intensity $(180 \mu \mathrm{A})$ for digitization. A matrix of $256 \times 256$ pixels was used in regions with a maximum area of $0.2 \times 0.2 \mathrm{~mm}^{2}$, resulting in a larger spatial resolution of the configuration $(0.8 \mu \mathrm{m})$. PIXE analysis made it possible to obtain distribution maps for $\mathrm{Al}, \mathrm{Si}, \mathrm{S}, \mathrm{K}, \mathrm{Ca}, \mathrm{Ti}, \mathrm{Mn}$ and $\mathrm{Fe}$. The carbon and oxygen concentrations were determined simultaneously by RBS analysis. The geochemical reference materials of the United States BCR2 (Basalt, Columbia River) and BIR1 (Icelandic basalt) were used for the validation of this quantification procedure.

\section{Results}

\subsection{Shapes, Edges and Discontinuities}

Shapes, edges and discontinuities of Akouemma hemisphaeria specimen consists of spheroidal and elongated shapes with either a "lateral budding", (Figure 4), or a "homogeneous lateral elongation" (Figures 5-7).

The spheroidal shapes, of diameter about $2 \mathrm{~cm}$ on average are characterized, whatever their size, by two hemispheres with their central nipple-like feature of the upper hemisphere and corresponding central depression of the lower hemisphere which likely correspond to a communication point between the two hemispheres separated by the median disc with its central orifice and its various rods or lamellae; the internal radial fabric is upwardly centrifugal in the upper hemisphere and downwardly centrifugal in the lower hemisphere (Figure 3, Movie 1, Movie 2) [8]. These spheroidal shapes have vertical axial symmetry; and the median zone usually has bi-concave surfaces on the hemispheres (Figure 1 (D0), 3) [7] [8].

The elongated shapes have a polar diameter similar to spheroidal shapes, the maximum length of the measured elongation axis exceeds just $6 \mathrm{~cm}$ (Figure 1 (D6, D7), 4, 6). These elongated specimens consist to several forms: elongated forms in single "piece"; elongated forms with "bud" to several pieces, and elongated double and triple specimens (Figure 1 (D1-D6), 4, 5, 6) [7] [8]. They have a bipartite structure with two hemispheres separated by an internal medial surface, and a median disc often visible at one or both ends of the specimens in vertical section (Figure 4(B), Figure 4(C), Figure 4(M), Figure 4(D), Figure 4(E), Figure 4(F), Figure 7); this median disc is visible in each "new specimen" in the horizontal section of the median zone (Figure 4(I), Figure 4(L), Figure 


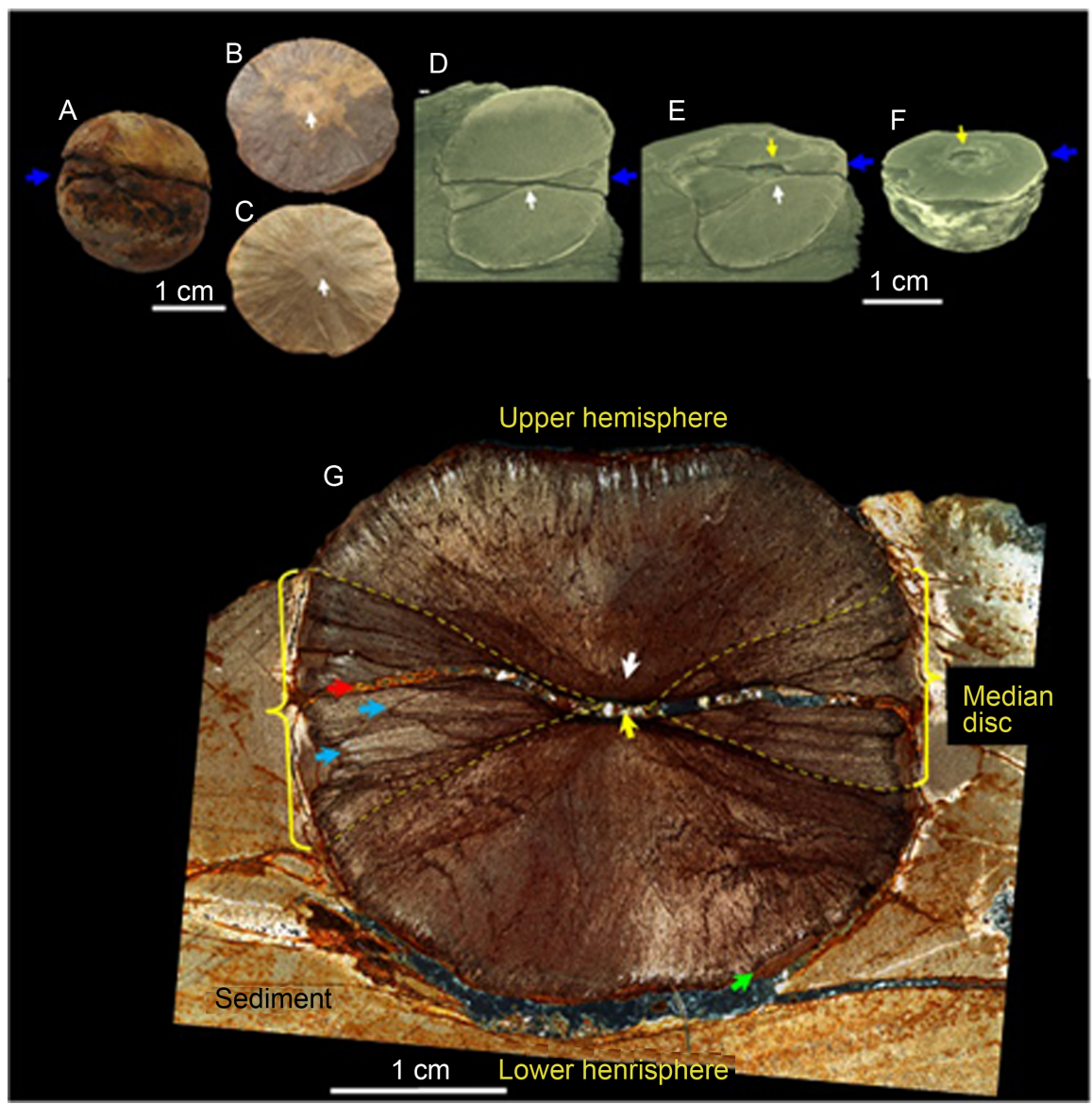

Figure 3. (A) Macroscopic view of spheroidal Akouemma hemisphaeria type showing a tripartite structure with a median disc (blue arrow) and two hemispheres. (B) Internal surface of an upper hemisphere, showing radial sculpture and a central nipple-like feature. (C) Internal surface of a lower hemisphere, showing radial sculpture and a corresponding central depression. (D) Tomographic vertical section view of spheroidal Akouemma hemisphaeria type partly in the sediment, showing the cracks delimiting the median disc (blue arrow); note the communication point (white arrow) between both hemispheres. (E) Tomographic view of the same sample showing a half the median disc (arrow blue) with its central orifice (yellow arrow); a half the lower hemisphere with its cone (white arrow). (F) Tomographic view of other sample showing a horizontal section of complete median disc (blue arrow) with its central orifice (yellow arrow), and the lower hemisphere. (G) Vertical thin section view of spheroidal Akouemma hemisphaeria type showing in the detail the two hemispheres and the median disc. Note the cones (white arrow) of hemispheres, the median disc orifice and the communication point (yellow arrow) between hemispheres, the different rods or lamellae of median disc (blue arrows), the secondary cracking (red arrow) of the median disc and the peripheral lenticular body (green arrow).

\section{5(H), Figure 5(L)).}

The spheroidal forms gradually pass to bud elongated specimens which may consist of two to four bonded "pieces", separated by hardly scored furrows (Figure $2\left(\mathrm{n}_{2}, \mathrm{n}_{5}\right)$, Figure 4, Figure $5(\mathrm{G})$, Figure 5(I)), or consisting of two to three contiguous "new specimens" separated by "constriction furrows" of varying degrees of depth according to their degree of division (Figure 1 (D2-D6), 


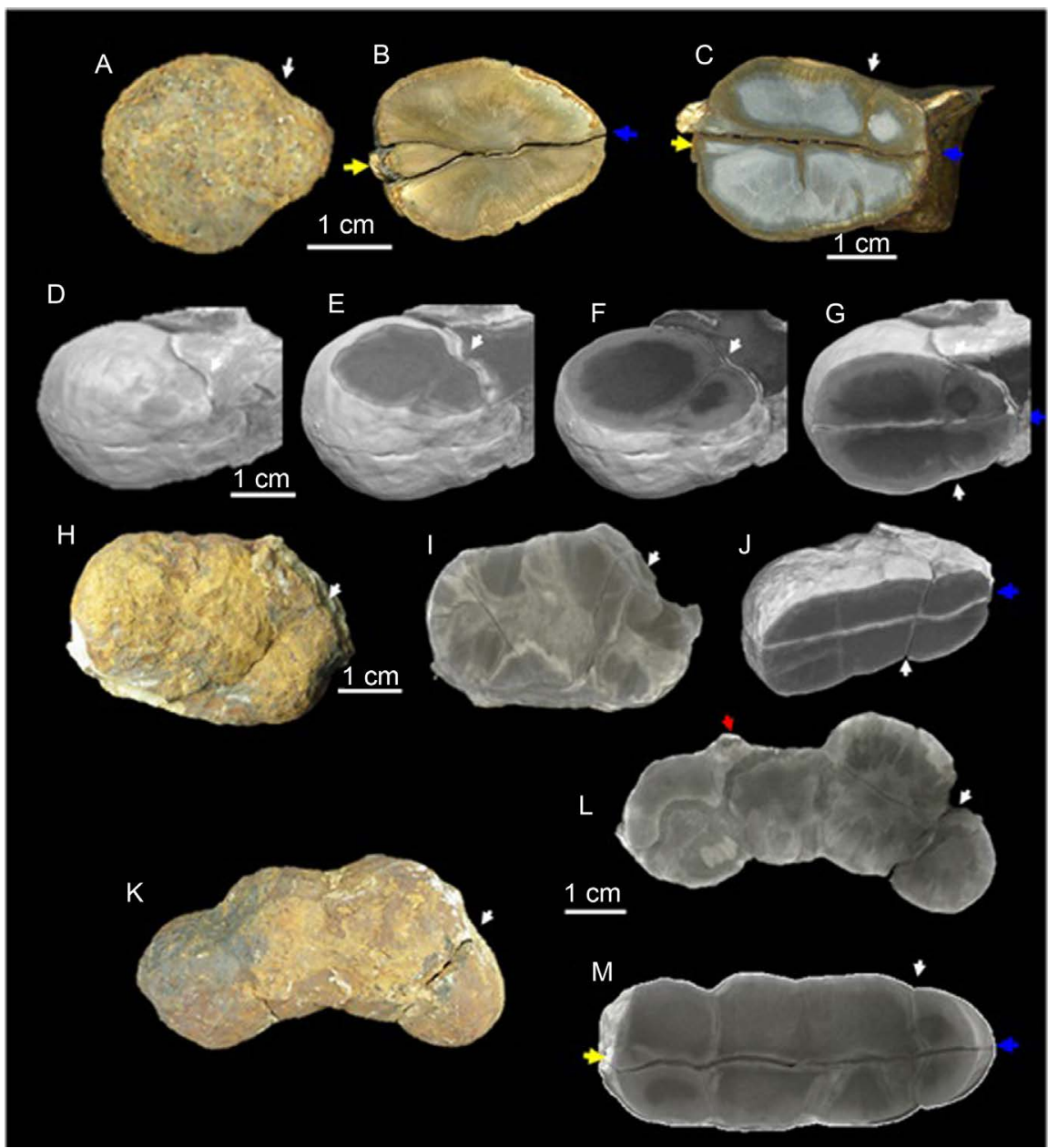

Figure 4. Different external and internal aspects of elongated specimens Akouemma hemisphaeria in growth phase by budding and likely by division. (A)-(B) Top view and vertical section of an ovoid specimen showing two hemispheres separated by a median surface, with a part of the "median disc" at the right end (yellow arrow). (C) Vertical section view of an elongate specimen showing a lateral bud, the limit of main specimen and the bud is hardly visible (white arrow), the median surface (blue arrow) is continuous over the whole of specimen. (D)-(G) Tomographic views of a specimen with a lateral bud, partially in the sediment. (D) Full specimen; (E)-(F) Horizontal section view of the upper hemisphere showing the limit of main specimen and the bud hardly visible in (E) and clearly visible in (F). (G) Vertical section view of the same specimen, note the continuous median surface over the whole specimen (blue arrow) and the limit between the main body and the bud. (H)-(I)-(J) Specimen with "three-bodies", (H) Macroscopic view showing barely visible limits between bodies, (I) horizontal tomographic view showing three internal "median disc", (J) Vertical tomographic view showing an internal median continuous surface on all specimen, the limits between the "bodies" are hardly visible. (K)-(L)-(M) Specimen with "four-bodies". (K) A macroscopic view with barely visible limits between "bodies" (L) A horizontal tomographic view showing four internal "median disc" with "raised border" (red arrow); (M) A vertical tomographic view showing an internal median continuous surface on all "bodies" (blue arrow), and on the right extremity, a part of the "median disc" (yellow arrow). The white arrows indicate the limits between the bud and the rest of the specimen.

Figure $2\left(n_{1}-n_{5}\right)$, Figure 5, Figure 6)). 


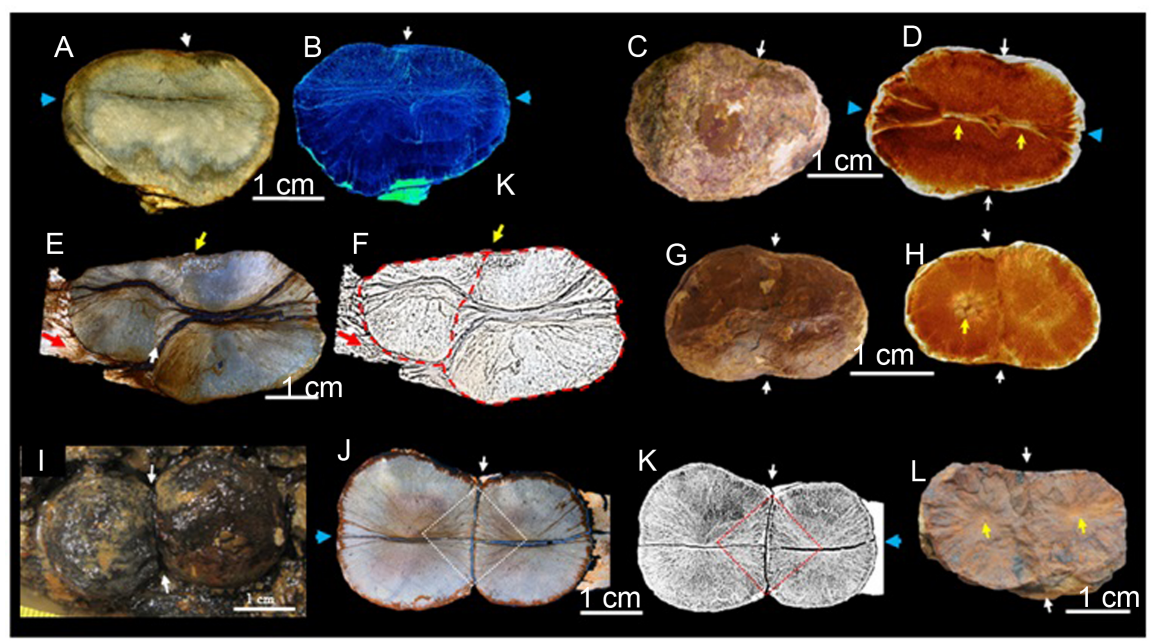

Figure 5. Different external and internal aspects of the elongated specimens Akouemma hemisphaeria in growth phase (homogeneous elongation) and duplication. (A) View of a polished vertical section of an elongated specimen AKOU 16 in a single piece with a flattened upper hemisphere, the internal median surface is barely visible. (B) Image Pixel of the $\mathrm{K}$ distribution map of same sample showing internal polygonal structure and a division plane (white arrow). (C)-(D) Akouemma elongated specimen in a single piece showing in (C) a top view of the hemisphere with a slight depression on the edge (white arrow); in (D) a tomographic view of the vertical section with two hemispheres separated by the median disc, note the two communication points probable between the two hemispheres (yellow arrow) and the internal polygonal structure (red arrow). (E)-(F) Vertical section of flattened elongated AKOU 35 specimen showing in (E) a flattening of the upper hemisphere (yellow arrow) and a folding of sediments below (red arrow); note the division plane in internal polygonal structure (white arrow), in (F) a scan of same sample shows a distorted internal structure of the upper hemisphere, including the internal polygonal structure; note the "duplication" of specimen (red dotted line). (G) Top view of the upper hemisphere clearly showing the furrow perpendicular to the elongated axis of the specimen. $(\mathrm{H})$ Tomographic view of same sample showing a lower hemisphere in a horizontal section parallel to the median surface with the division plane between two "bodies" that connects the edge furrow, note a central depression in the left "body" (yellow arrow), it is barely visible in the right "body". (I)-(J)-(K) Different external and internal aspects of a double specimen. (I) Macroscopic view of the top of the double specimen in the field showing two "attached new specimens"; note the deep furrow that separates them. (J) Vertical section of the same sample through two conjoined "new specimens" showing weathered margin, radial fabric and division planes; note the polygonal structures on either side of the division plane (white frame). (K) Same sample, the internal structure is highlighted by the distribution of the $\mathrm{K}$ which shows perfectly the polygonal structure on the two "new specimens" (red frame) suggesting the end of the likely 'duplication' process. (L) Macroscopic top view of double specimen median zone, showing in relief the junction (division plane) between the two specimens in formation (white arrows); note the communication point of each specimen (yellow arrows).

\subsection{Boundaries and Discontinuity}

Four types of "boundaries" and discontinuity are observed on the specimens: border, median surface, transverse constriction furrow (constriction zone), and vertical division plane in the elongated forms.

The border (outer) of the specimens is always net; it is net on contact with 


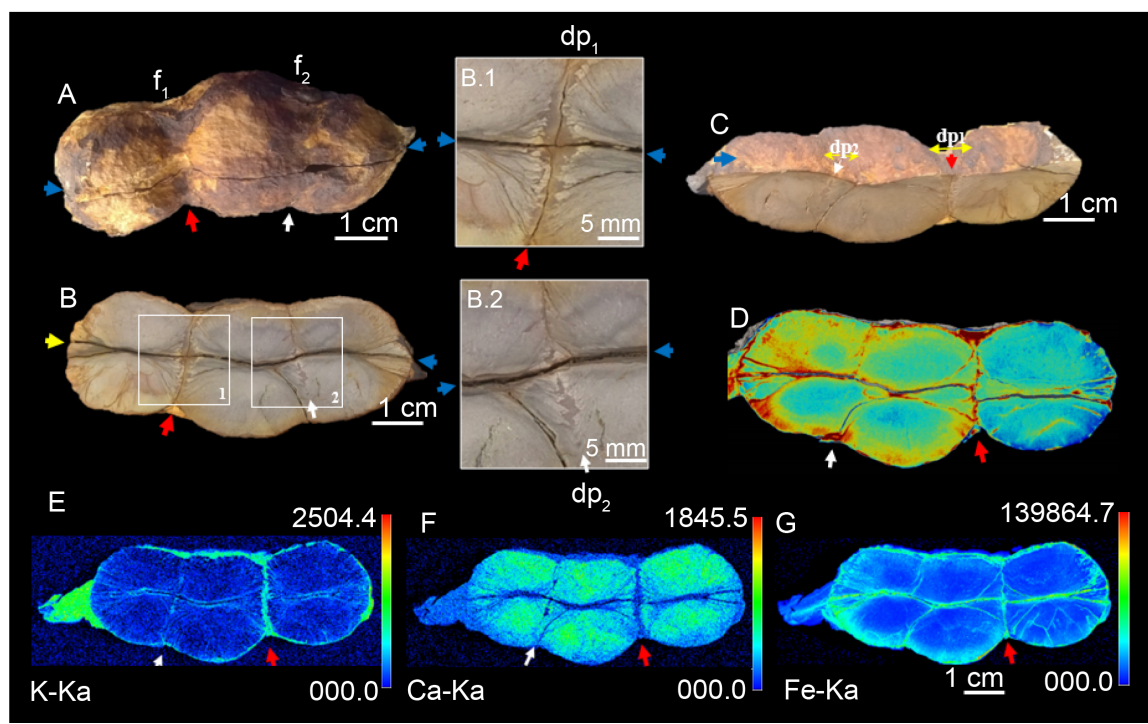

Figure 6. Different external and internal aspects of the elongated specimen Akouemma hemisphaeria with triple "new specimens" in growth phase (homogeneous elongation) and fission (duplication). (A) Macroscopic view of the elongated specimen showing two hemispheres separated by a median surface (blue arrows); note the two furrows, one of which is fairly deep furrow $1\left(\mathrm{~S}_{1}\right.$ red arrow) and the other shallow, furrow 2 ( $\mathrm{S}_{2}$ white arrow) around the specimen. (B) Vertical polished section of the same sample showing two division planes, one is more developed (division plane 1, red arrow) and shows a sharper limit between the "bodies"; note the polygonal structure on either side of each division plane; and the other is slightly developed (division plane 2, white arrow) and draws an incomplete limit between the "bodies" with a polygonal structure less developed; note the median disc at the ends of the specimen. (B1)-(B2) Details of division plane 1 (dp1) and 2 (dp2) respectively showing a clear division (separation) of the specimen and a beginning of division (separation) of the same specimen; the median surface is continuous on either side of the "division plane" (blue arrows). (C) Longitudinal view of one half of the sample (B) showing half of the median surface (blue arrow) continuously along the specimen. (D) Tomographic view of sample (B) showing clear separation (red arrow) of blue "body", and incomplete separation of others (white arrow). (E)-(G) K, Ca, and Fe distribution maps showing a distinction between the specimen and the sediment, and show the complete separation of the right "new specimen" (red arrow) and incomplete separation of the others (white arrow); the Fe and Ca distribution maps in the right-detached "new specimen" clearly show its tripartite structure with two hemispheres and "median disc".

sediments and on contact with other specimens (Figure 1(D), 2-8)). Two or more contiguous "independent" specimens are generally deformed at their contact surfaces (Figure 1 (D8), 8)) [7] [8]. An alignment of six specimens in chain, in the sedimentary plate P01, presents six joined and deformed specimens and a well-developed, undeformed specimen located in the middle of the chain (Figure 8(I)). The deformed specimens located on either side of the well-developed specimen have varying degrees of deformation. The deformations between specimens are essentially deformations by crushing due to lateral mutual compression between them; which is sometimes very accentuated and lead to significant volume reduction, matter spreading, flexion, micro-folding and sometimes rotation of hemispheres and median disc (Figure 8). Some spe- 
cimens show deformations by more or less pronounced flattening of the upper hemisphere without deformation of the lower hemisphere (Figure 5(A), Figure 5(B), Figure 5(E), Figure 5(F)). Flattened shapes, due to vertical compression, are sometimes observed on some specimens (Figure 10(F)) [7] [8].

The internal medial surfaces are located in the median zone, and laterally separate the two hemispheres from the median disc. Spheroidal forms generally have bi-concave surfaces on the median disc, or biconvex on the internal surfaces of the hemispheres (Figure 1 (D0), Figure 3(B) \& Figure 3(C)), and usually horizontal between the two hemispheres in elongated form (Figure 4(C), Figure $4(\mathrm{G})$, Figure 4(J), Figure 4(M)), Figure 5(A), Figure 5(B), Figures 5(D)-(F), Figure 5(J), Figure 5(K)), Figure 6) [7] [8].

The external furrows of "constriction" and the internal vertical division planes generally separate two contiguous "pieces" of the same elongated specimen containing several "pieces". These two structures are always associated and form a partition between two contiguous "pieces" in a bud elongate specimens (Figure 4 ), the external furrows are very little marked, and are joined to the internal vertical division planes (Figure 4(C), Figures 4(E)-(G), Figure 4(J), Figure 4(M)). In elongated double and triple specimens, the external furrows and the "division planes" are more or less well developed depending on the degree of separation of the new specimens (Figure 5, Figure 6). The external furrow (which would correspond to a constriction) is growing deeper and the increasingly net separation between new specimens when passing from elongated shapes into a single "piece" to the double and triple specimens (Figure 5, Figure 6). The junction of the median discs of two new specimens in these double and triple specimens form an internal polygonal structure whose "division plane" is the symmetry plane (Figure 5(B), Figures 5(J)-(L)), Figure $6\left(b, b_{1}, b_{2}, d, f, g\right)$ ), (Movie 3 ). The triple elongated specimen (Figure 6) illustrate perfectly the different degrees of separation of the new specimens, with one side, an incomplete separation of the specimen and on the other, a distinct separation with formation of an ovoid new specimen with two hemispheres and a median disc. The case of Akouemma hemisphaeria OKO 3 in single "piece" is particular with two polygonal structures and two internal division planes which develop simultaneously (Figure 7(A), Figure 7(B)).

\section{Discussion}

Akouemma hemisphaeria specimens have been described as macrofossils according to the following criteria:

- Homogeneous form and size that consist of two hemispheres with their central nipple-like feature of the upper hemisphere and corresponding central depression of the lower hemisphere. The central nipple-like feature and the corresponding central depression likely correspond to a "communication point" between the two hemispheres which are separated by the median disc with its central orifice; 


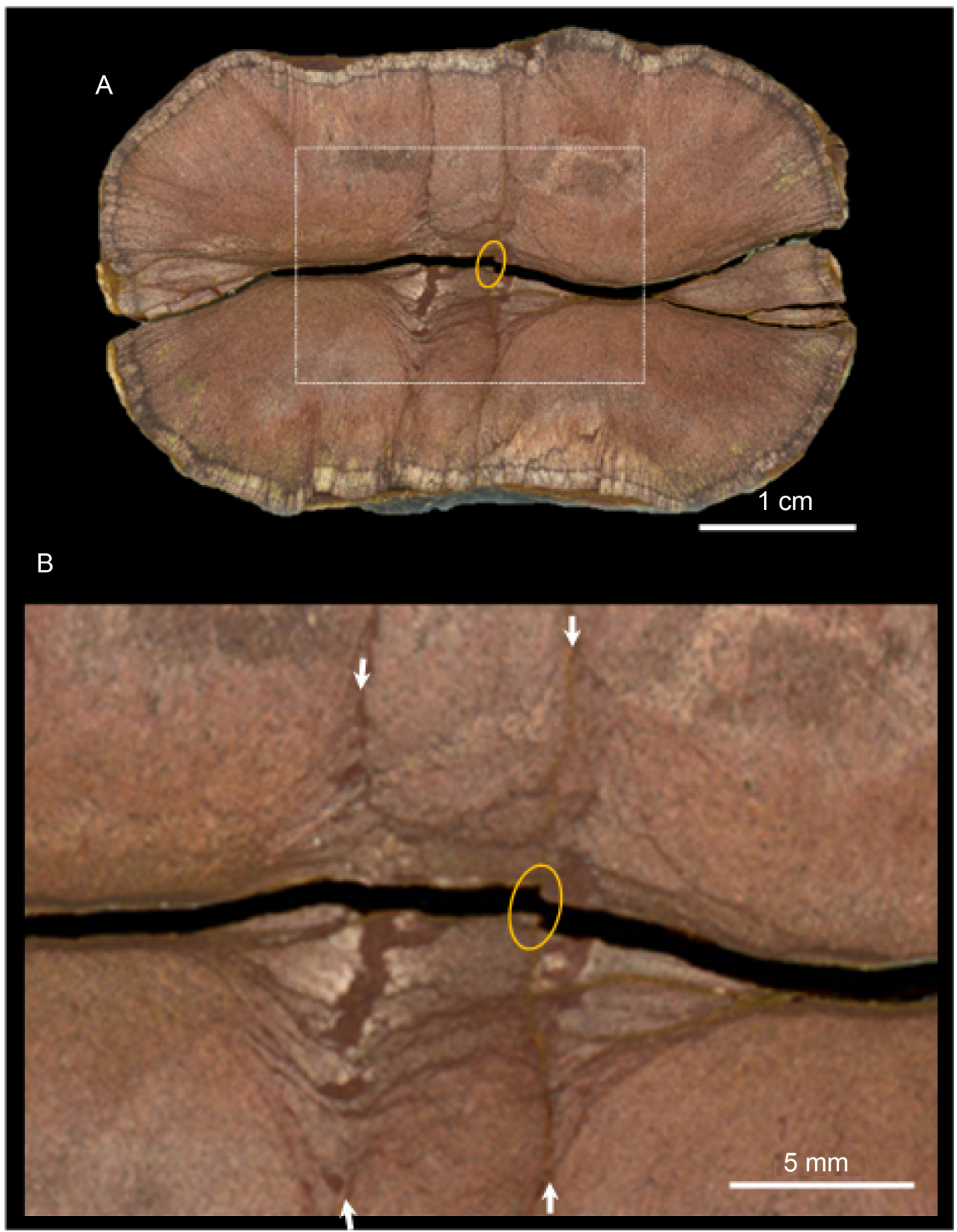

Figure 7. (A) Vertical section view of elongated Akouemma hemisphaeria OKO 3 in single "piece", showing in its central part two division planes (white box). (B) Detail of the central zone showing two polygonal structures with two division planes (white arrows). The two notches in the yellow circle indicate that the two hemispheres were initially joined by the median surface, as in Figure 4(B), Figure 4(C), Figure 4(G), Figure 4(J), Figure 4(M)).

- Centrifugal internal fabric radiates from the cones of each hemisphere in spheroidal specimens and a polyphase internal fabric with an internal polygonal structure in elongated forms, highlighted by Al-K-(Ti)-rich clay minerals in close association with carbon particles and by $\mathrm{Ca}$ calcite and $\mathrm{Fe}$ oxides-sulphides;

- Uniformly distribution of silica (micro-quartz) in all specimens (distorted or not) that have fossilized microorganisms, and initial states including deformations, degradations and internal degrees of dispersion and spreading of particles and fragments in the specimens; 
- Mutual flexible deformations which strongly affect specimens, including radial internal fabric, with spreading of matter and deformation of sediments around and between specimens in bedding planes, suggesting growth in soft sediments;

- Elongated specimens that show signs of division marked by the presence of external furrows (constriction zone) that become increasingly deep with the progression from elongated shapes in single pieces to segmented elongated forms, with individualization of new spheroidal bodies [7] [8].

So, the morphological, structural and geochemical criteria of the macrofossils Akouemma hemisphaeria show that their fossilization was made on different life cycle stages.

These different forms of Akouemma hemisphaeria show a variety of situations: spheroidal specimens, elongated specimens with bud, elongated specimens in a lateral direction with several "pieces" without deformation, deformed contiguous specimens as well as deformations of surrounding sediments.

These situations highlight three processes: 1) a progressive growth process, 2) a fission process leading to the formation of new spheroidal specimens, and 3) a lateral mutual compression process causing deformations of contiguous independent specimens.

These processes demonstrate some ductility of these organisms in unconsolidated soft sediments. The deformations of the specimens coming mainly from lateral compressions of the latter would be linked to their growth. This growth results by a lateral budding of specimens that may lead to the formation of elongated multi-pieces specimens (Figure 4) and probably to the formation of small specimens following an early detachment of the bud; or by the formation of "double and triple" specimens by homogeneous lateral elongation and division with individualization of new spheroidal specimens of almost identical size (Figure 5, Figure 6). The internal polygonal structures of the elongated shapes would result from the materialization of the median discs of the two contiguous new specimens.

Although the constitution, size and living environment very different, the external morphology presenting undeformed isolated specimens, coupled by two, by three, in chain and deformed by lateral mutual compression observed inAkouemma hemisphaeria contained in undeformed tabular beds (Figure 8, Figure 9(A), Figure $10\left(e_{1}-e_{5}\right)$ ), (Movie 4), [7] [8], is similar to the external morphology observed in the current apothecia of crustacean lichens of Chile fixed on a non-deformed support (Figure 9(B)). These apothecia of crustacean lichens, which are far from being Akouemma hemispharia modern analogues and showing no fission sign, clearly show the apothecia undergo deformations by mutual lateral compression linked to their growth (Figure 9(B)). This confirms that the mutual deformations by lateral compression observed in Akouemma hemisphaeria occurred on the fixed or sessile organisms at soft-plastic body comparable to that of these apothecia. 

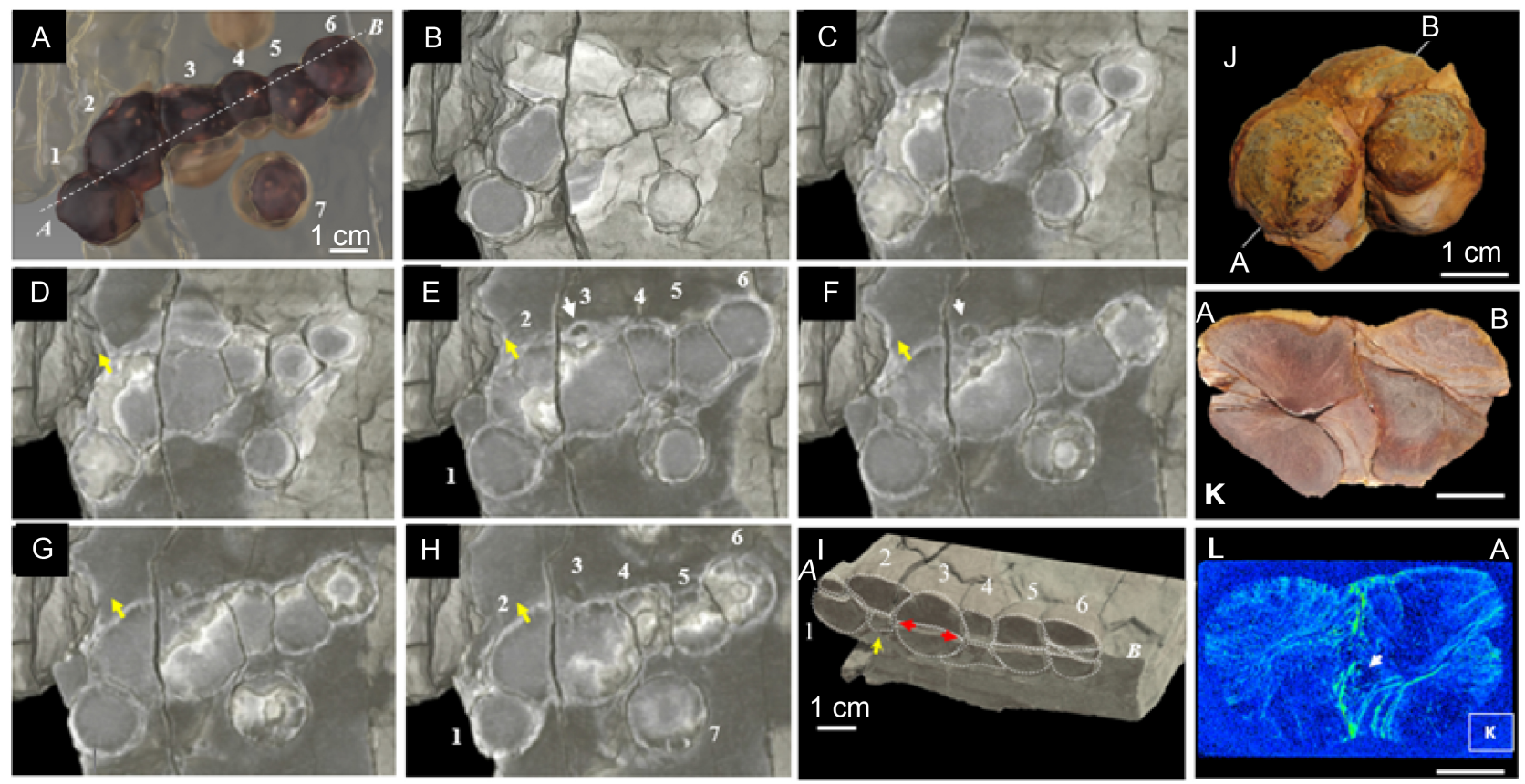

Figure 8. Different external and internal aspects of ovoid specimens in growth phase and compression in an undeformed tabular sedimentary plate containing undeformed isolated specimens, and deformed specimens in a chain. (A) Transparent tomographic view of the same plate showing the chain of six joined and deformed specimens ( 1 - 6), undistorted isolated specimen (7), with a cutting line (ab) on the chain. (B)-(H) Tomographic view of the lateral sections (top down) of the six specimens in chain and specimen 10; note the lateral spreading of matter within specimen 2 (yellow arrows); the specimen 10, adjoined to the deformed specimens in chain, does not present any deformation and highlights the median disc when moving from the upper hemisphere (B) to the lower hemisphere (H). (I) Tomographic view of the vertical section (ab) showing the more-or-less intense deformations of the specimens; note the significant reduction in volume of the lower hemisphere of specimen 2 (yellow arrow), the fan-shaped spreading upward of its upper hemisphere, and the fan-shaped spreading downward of lower hemisphere of specimen 4; much of the lateral constraint would come from specimen 3 (red arrows), well developed and showing no deformation. (J)-(L) Three other contiguous and deformed specimens. (J) Together, the three specimens present deformed contact surfaces. (K) Vertical section of two specimens with a highly deformed contact surface. (L) The same sample, the potassium distribution map highlights the deformations of the internal structure of specimens. Note the encrusted "oblong-shaped bodies" bordering the specimens (white arrows).
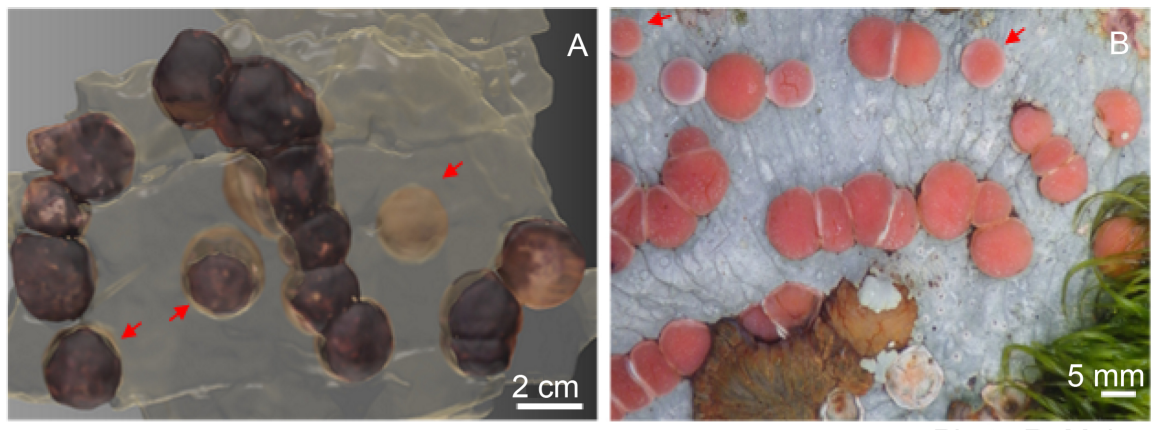

Photo R. Maire

Figure 9. (A) Transparent tomographic view of an un-deformed sedimentary plate containing paleoproterozoic macro-fossils Akouemma hemisphaeria, isolated un-deformed (red arrows), in pairs, by three and deformed in contiguous specimens in chain. (B) Macroscopic view of the current apothecia crustacean lichens of Patagonia fixed on undeformed support, isolated undeformed (red arrow), in pairs, by three deformed in contiguous specimens in chain. 


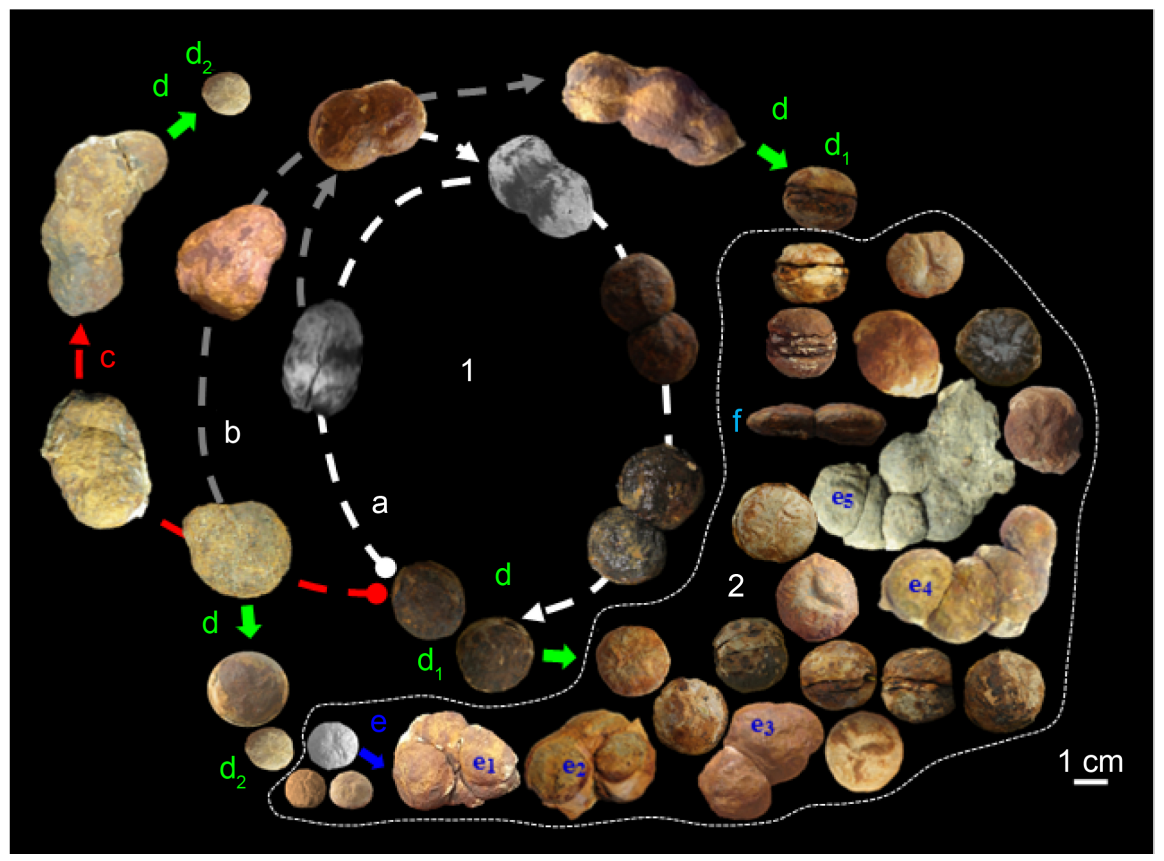

Figure 10. Life cycle: (1) growth, budding, fission; and (2) accumulation, growth and compressive deformation of Akouemma hemisphaeria. (a)-(b): growth by lateral elongation, then division with probable formation of two or three almost identical "bodies" $\left(\mathrm{d}_{1}\right)$. (c): growth by lateral "budding" with successive formation of "body" with sometimes probable detachment of the bud $\left(d_{2}\right) .(d)$ : $\left(d_{1}\right)$ : duplication after "homogeneous elongation"; $\left(\mathrm{d}_{2}\right)$ : duplication after budding, and bud detachment. (e): growth and lateral mutual compression, $\left(\mathrm{e}_{1}-\mathrm{e}_{5}\right)$. (f): vertical flattening probably by burial compaction.

The growth process by budding, recalls that of unicellular organisms like yeast [17] [18] or that of basic metazoan organisms like Cnidarian polyps, Jelly fish [19], Scyphozoa [20] and Hydra [21]. Similarly, the fission process recalls the cell division of microorganisms such as algae [22], protozoa [23] and Archean micro-organism [24], or the duplication of primitive metazoans as enigmatic macrofossils of late Ediacaran [25], Echinoderm Holothuria (sea cucumbers) [26] [27] [28] [29] and anemones [30] [31]. The time-scale of Akouemma hemisphaeria life cycle remains indeterminate; it could be comparable to the current primary metazoans although the latters have a sexual reproduction in their life cycle. These include anemones that may have sexual and asexual reproductions [32] [33] [34] or exclusively asexual reproduction [35] [36]. They can create a colony of several dozens of anemones in a few years from a single individual after following a succession of duplications [35].

\section{Conclusions}

Based on the observations of the colony of sessile macrofossils Akouemma hemisphaeria in the sedimentary formations of Okondja Basin at $2.2 \mathrm{Ga}$, we conclude that:

1) The life cycle development of Akouemma hemisphaeria can be summarized as follows (Figure 10): 
a) Growth by lateral homogeneous elongation or by lateral budding with formation of double or triple specimens and which divides into two or three almost identical specimens. This process seems to be the most common (Figure 10 (a-b, d- $\left.\left.d_{1}\right)\right)$.

b) Growth by lateral "budding" with successive formation of "pieces" which remain generally attached to each other; or by budding followed by a probable detachment of the bud to form a new son specimen generally smaller (Figure 10 $\left.\left(c, d-d_{2}\right)\right)$.

c) Growth and lateral compression, this mechanism is the consequence of the proliferation of contiguous specimens. A high density of joined "new specimens" prevents their optimal growth, causing deformations by lateral mutual compression between specimens, and deformation of the surrounding sediment (Figure $\left.10\left(\mathrm{e}_{1}-\mathrm{e}_{5}\right)\right)$; in other words, the deformations by lateral mutual compression observed in Akouemma hemisphaeria are due to their growth.

2) Akouemma hemisphaeria had vegetative growth and asexual reproduction by budding or lateral elongation and fission, reveal the oldest duplication of macro-organisms and consist a milestone of the fossil record as they show a significant life cycle in the Paleoproterozoic age.

The Francevillian Group in Gabon, containing the earliest macrofossils, is the key to solve the Paleoproterozoic biosphere.

\section{Acknowledgements}

We thank Harumasa Kano (Tohoku University Museum) for performing the micro-CT analysis. This research was partly supported by a grant for "Hadean Bioscience (No. 26106002)" from the Japan Society for the Promotion of Science (JSPS).

\section{References}

[1] Kopp, R.E., Kirschvink, J.L., Hilburn, I.A. and Nash, C.Z. (2005) The Paleoproterozoic Snowball Earth: A Climate Disaster Triggered by the Evolution of Oxygenic Photosynthesis. Proceedings of the National Academy of Sciences of the United States of America, 102, 11131-11136. https://doi.org/10.1073/pnas.0504878102

[2] Holland, H.D. (2006) The Oxygenation of the Atmosphere and Oceans. Philosophical Transactions of the Royal Society: Biological Sciences, 361, 903-915. https://doi.org/10.1098/rstb.2006.1838

[3] Knoll, A.H., Javaux, E.J., Hewitt, D. and Cohen, P. (2006) Eukaryotic Organisms in Proterozoic Oceans. Philosophical Transactions of the Royal Society of London. Series $B$, 361, 1023-1038. https://doi.org/10.1098/rstb.2006.1843

[4] Han, T.M. and Runnegar, B. (1992) Megascopic Eukaryotic Algae from the 2.1-Billionyear-Old Negaunee Iron-Formation, Michigan. Science, 257, 232-235. https://doi.org/10.1126/science.1631544

[5] Retallack, G.J., Krull, E.S., Thackray, G.D. and Parkinson, D. (2013) Problematic Urnshaped Fossils from a Paleoproterozoic (2.2 Ga) Paleosol in South Africa. Precambrian Research, 235, 71-87. 
[6] Albani, A.E.L., Bengtson, S., Canfield, D.E., Bekker, A., Macchiarelli, R., Mazurier, A., Hammarlund, E.U., Boulvais, P., Dupuy, J.-J., Fontaine, C., Fursich, F.T., Gauthier-Lafaye, F., Janvier, P., Javaux, E., Ossa, F.O., Pierson-Wickmann, A.-C., Riboulleau, A., Sardini, P., Vachard, D., Whitehouse, M. and Meunier, A. (2010) Large Colonial Organisms with Coordinated Growth in Oxygenated Environments 2.1 Gyr Ago. Nature, 466, 100-104. https://doi.org/10.1038/nature09166

[7] Moussavou, M., Edou-Minko, A., Mbina Mounguengui, M., Ortega, R., Fleury, G., Roudeau, S., Carmona, A., Genty, D., Blamart, D., Tchikoundzi, C., Makaya, M., Musavu Moussavou, B., Ndong Ondo, S., Ogandaga Agondjo, M., Dewilde, F., Delorme, G., de Parseval, P., Weil, R. and Maire, R. (2015) Multicellular Consortia Preserved in Biogenic Ductile-Plastic Specimens of Okondja Basin (Gabon) by 2.1 Ga. Journal of Geosciences, 4, 195. https://doi.org/10.4172/2329-6755.1000195

[8] Edou-Minko, A., Moussavou, M., Sato, T., Tchikoundzi, C., Sawaki, Y., Ndong Ondo, S., Ortega, R., Maire, R., Kaestner, A., Mbina Mounguengui, M., Roudeau, S., Fleury, G., Carmona, A., de Parseval, P.H., Mvoubou, M., Musavu Moussavou, B., Ogandaga Agondjo, M., Sasaki, O. and Maruyama, S. (2017) An Akouemma hemisphaeria Organic Macrofossils Colony Hosting Biodiversity Assemblage on the Seafloor of Okondja Basin (Gabon) Dated at 2.2 Ga. Journal of Geology \& Geophysics, 6, 281. https://sites.google.com/site/tomopikosato/supplement http://doi.org/10.4172/2381-8719.1000281

[9] Sawaki, Y., Moussavou, M., Sato, T., Suzuki, K., Ligna, C., Asanuma, H., Sakata, S., Obayashi, H., Obayashi, H., Hirata, T. and Edou-Minko, A. (2017) Chronological Constraints on the Paleoproterozoic Francevillian Group in Gabon. Geoscience Frontiers, 8, 397-407.

[10] Anderson, I.S., McGreevy, R.L. and Bilheux, H.Z. (2009) Neutron Imaging and Applications. Springer Verlag, New York.

[11] Kaestner, A., Vontobel, P. and Lehmann, E. (2010) Neutron Imaging Methods in Geoscience. Adv Comput Tomogr Geomater, 352-365.

[12] Laaß, M. and Kaestner, A. (2017) Evidence for Convergent Evolution of a Neocortex-Like Structure in a Late Permian Therapsid. Journal of Morphology, 278, 1033-1057. https://doi.org/10.1002/jmor.20712

[13] Laaß, M., Schillinger, B. and Kaestner, A. (2017) What Did the "Unossified Zone" of the Non-Mammalian Therapsid Braincase House? Journal of Morphology, 278, 1020-1032. https://doi.org/10.1002/jmor.20583

[14] Kaestnera, A.P., Hartmanna, S., Kühne, G., Frei, G., Grunzweig, C., Josic, L., Schmid, F. and Lehmann, E.H. (2011) The ICON Beamline-A Facility for Cold Neutron Imaging at SINQ. Nuclear Instruments and Methods in Physics Research Section A: Accelerators, Spectrometers, Detectors and Associated Equipment, 659, 387-393.

[15] Burger, M., Gilboa, G., Osher, S. and Xu, J. (2006) Nonlinear Inverse Scale Space Methods. Communications in Mathematical Sciences, 4, 179-212. https://doi.org/10.4310/CMS.2006.v4.n1.a7

[16] Ortega, R., Maire, R., Devès, G. and Quinif, Y. (2005) High-Resolution Mapping of Uranium and Other Trace Elements in Recrystallized Aragonite-Calcite Speleothems from Caves in the Pyrenees (France): Implication for U-Series Dating. Earth and Planetary Science Letters, 237, 911-923.

[17] Schmidt, M., Bowers, B., Varma, A., Roh, D.H. and Cabib, E. (2002) In Budding Yeast, Contraction of the Actomyosin Ring and Formation of the Primary Septum at Cytokinesis Depend on Each Other. Journal of Cell Science, 115, 293-302. 
[18] Balasubramanian, M.B.E. and Glotzer, M. (2004) Comparative Analysis of Cytokinesis in Budding Yeast, Fission Yeast and Animal Cells. Current Biology, 14, R806-R818.

[19] Han, C.H. and Uye, S.I. (2010) Combined Effects of Food Supply and Temperature on Asexual Reproduction and Somatic Growth of Polyps of the Common Jellyfish Aurelia Aurita Sl. Plankton and Benthos Research, 5, 98-105. https://doi.org/10.3800/pbr.5.98

[20] Schiariti, A., Morandini, A.C., Jarms, G., von Glehn Paes, R., Franke, S. and Mianzan, H. (2014) Asexual Reproduction Strategies and Blooming Potential in Scyphozoa. Marine Ecology Progress Series, 510, 241-253. https://doi.org/10.3354/meps10798

[21] Domazet-Lošo, T., Klimovich, A., Anokhin, B., Anton-Erxleben, F., Hamm, M.J., Lange, C. and Bosch, T.C. (2014) Naturally Occurring Tumours in the Basal Metazoan Hydra. Nature Communications, 5, Article No. 4222.

https://doi.org/10.1038/ncomms5222

[22] Barsanti, L. and Gualtieri, P. (2014) Algae: Anatomy, Biochemistry, and Biotechnology. CRC Press. https://doi.org/10.1201/b16544

[23] Preer, J.R. (2015) Genetics of the Protozoa. Research in Protozoology, 1, 129-278.

[24] Sugitani, K., Mimura, K., Takeuchi, M., Lepot, K., Ito, S. and Javaux, E.J. (2015) Early Evolution of Large Micro-Organisms with Cytological Complexity Revealed by Microanalyses of 3.4 Ga Organic-Walled Microfossils. Geobiology, 13, 507-521. https://doi.org/10.1111/gbi.12148

[25] Mitchell, E.G., Kenchington, C.G., Liu, A.G., Matthews, J.J. and Butterfield, N.J. (2015) Reconstructing the Reproductive Mode of an Ediacaran Macro-Organism. Nature, 524, 343-346. https://doi.org/10.1038/nature14646

[26] Laxminarayana, A. (2006) Asexual Reproduction by Induced Transverse Fission in the Sea Cucumbers Bohadschia marmorata and Holothuria atra. SPC Beche-de-Mer Information Bulletin, 23, 35-37.

[27] Lee, J., Byrne, M. and Uthicke, S. (2008) The Influence of Population Density on Fission and Growth of Holothuria atra in Natural Mesocosms. Journal of Experimental Marine Biology and Ecology, 365, 126-135.

[28] Dolmatov, I.Y. (2014) Asexual Reproduction in Holothurians. The Scientific World Journal. https://doi.org/10.1155/2014/527234

[29] Sonnenholzner, J.I., Searcy-Bernal, R. and Panchana-Orrala, M. (2017) The Potential for Propagation of the Commercial Sea Cucumber Isostichopus Fuscus (Ludwig, 1875) by Induced Transverse Fission. Regional Studies in Marine Science, 9, 35-42.

[30] Haeussermann, V., Spano, C., Thiel, M. and Lohrmann, K.B. (2015) First Record of the Sea Anemone Diadumene lineata (Verrill, 1869) from the Chilean Coast. SPIXIANA, 38, 39-42.

[31] Scott, A. (2017) Sea Anemones. In: Marine Ornamental Species Aquaculture, 437-456. https://doi.org/10.1002/9781119169147.ch21b

[32] Bocharova, E.S. and Kozevich, I.A. (2011) Modes of Reproduction in Sea Anemones (Cnidaria, Anthozoa). The Biological Bulletin, 38, 849-860. https://doi.org/10.1134/S1062359011090020

[33] Schnytzer, Y., Giman, Y., Karplus, I. and Achituv, Y. (2017) Boxer Crabs Induce Asexual Reproduction of Their Associated Sea Anemones by Splitting and Intraspecific Theft. PeerJ, 5, e2954. https://doi.org/10.7717/peerj.2954

[34] Reilly, E.E. and Chadwick, N.E. (2017) Population Dynamics of Corkscrew Sea 
Anemones Bartholomea annulata in the Florida Keys. Marine Ecology Progress Series, 567, 109-123. https://doi.org/10.3354/meps12032

[35] Häussermann, V. and Försterra, G. (2001) A New Species of Sea Anemone from Chile, Anemonia alicemartinae n. sp. (Cnidaria: Anthozoa) An Invader or an Indicator for Environmental Change in Shallow Water? Organisms Diversity and Evolution, 1, 211-224. https://doi.org/10.1078/1439-6092-00018

[36] Spano, C. and Häussermann, V. (2017) Anthopleura Radians, a New Species of Sea Anemone (Cnidaria: Actiniaria: Actiniidae) from Northern Chile, with Comments on Other Species of the Genus from the South Pacific Ocean. Biodiversity and Natural History, 3, 1-11.

\section{Appendix}

Link of the four movies to the website address:

Movie 1:

https://sites.google.com/site/tomopikosato/supplement/Film 1. Akouemma ovoid form.mp4?attredirects $=0 \& \mathrm{~d}=1$

Movie 2:

https://sites.google.com/site/tomopikosato/supplement/Film 2. Akouemma SV3 ovoid form-2.mp4?attredirects $=0 \& \mathrm{~d}=1$

Movie 3:

https://sites.google.com/site/tomopikosato/supplement/Film 3. Akou \%2816\%29-division zone.m4v?attredirects=0\&d=1

Movie 4:

https://sites.google.com/site/tomopikosato/supplement/Film\%204.Transversal_S lices $\% 20$ Plate $\% 2001 . \mathrm{mp} 4$ ? attredirects $=0 \& \mathrm{~d}=1$

\section{Scientific Research Publishing}

Submit or recommend next manuscript to SCIRP and we will provide best service for you:

Accepting pre-submission inquiries through Email, Facebook, LinkedIn, Twitter, etc. A wide selection of journals (inclusive of 9 subjects, more than 200 journals)

Providing 24-hour high-quality service

User-friendly online submission system

Fair and swift peer-review system

Efficient typesetting and proofreading procedure

Display of the result of downloads and visits, as well as the number of cited articles

Maximum dissemination of your research work

Submit your manuscript at: http://papersubmission.scirp.org/

Or contactijg@scirp.org 